\title{
Preface
}

\section{The Future of Pharmacology in Anesthesia Practice}

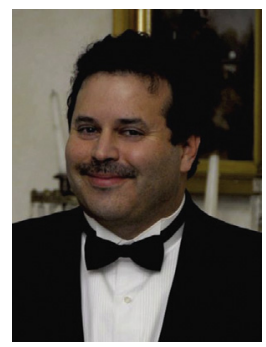

Alan D. Kaye, MD, PhD, DABA, DABPM, DABIPP

Editor

As a second year medical student, my oldest child, Aaron, recently started his pharmacology course at the Medical University of South Carolina in Charleston. Though the first lecture on pharmacokinetics left him terrorized, over time, he saw the wonders of understanding how drugs work in the human body. So much so, at present, he is considering a career as a future anesthesiologist.

This excites me because as he learned about the adrenergic system, I explained how my wife was placed on terbutaline, my favorite drug in the world, which relaxed her uterus, and gave my son and daughter, who is currently an undergraduate and premed student herself, safe passage into this world. In fact, who among us cannot appreciate the greatness of pharmacology in our lives?

Thinking back over my clinical career as an anesthesiologist, intensivist, and pain specialist, I have seen the wonders of pharmacology first hand and am delighted to share a very diverse group of articles focused on different drug considerations. Some of these topics are focused on subpopulations, including pediatrics, the obese, and geriatrics. For all of these varied patients, it is clear that there are very different pharmacokinetics and physiology in these groups, and I hope these reviews are meaningful for your practices.

There are focuses on different and important groups of drugs related to our field. Reviews in this issue include updates on novel anesthetics, opioid agents, local anesthetics, antiemetics, anticoagulants and their reversal, total parenteral nutrition, nonopioid intravenous or oral analgesics, uterotonic medications, pulmonary vascular mediating drugs, alpha 2 modulators, cardiovascular drugs, octreotide, nonsteroidal anti-inflammatory and steroid medications. In addition, there are interesting reviews on pharmacogenomics of pain and anesthesia, allowing us to look at our field in a different and futuristic manner.

Finally, we have included a special review as well on the basic pharmacology of oxycodone with a special emphasis on pharmacokinetic/pharmacodynamic properties. In 
addition, a special review is provided on the controversy regarding oxycodone-mediated or modulated effects for visceral pain via agonism, and the possible role or roles of peripheral opioid analgesia is discussed.

Our authors come from outstanding institutions from around the country, and I am especially thankful to Dr Lee Fleisher, Professor and Chairman of Anesthesiology at the University of Pennsylvania and my good friend, for giving me yet another opportunity to edit this series, and Dr Jonathan Jahr, a professor at UCLA and my longtime friend, for serving as a liaison and mentor on many of these review articles. I also want to thank the many members of my beloved LSU Department of Anesthesiology in New Orleans, who worked on a wide range of topics for this issue.

The future in anesthesiology is bright because of the development of newer and safer drugs and advancements in technology. We are living at a time where miracles happen in our operating rooms, in our intensive care units, and in pain management on a daily basis. Yet to come, we will have even more exciting opportunities to make a difference in the care of our patients with newer drugs and therapeutic options in the treatment of diseases and in the operating room. In this spirit, let us rededicate ourselves to our practices in medicine and find time always to have balance in our lives as we move forward to the future!

Alan D. Kaye, MD, PhD, DABA, DABPM, DABIPP

Department of Anesthesiology and Pharmacology

Anesthesiology Services

University Medical Center Hospital

Louisiana State University School of Medicine T6M5

1542 Tulane Avenue, Room 656

New Orleans, LA 70112, USA

E-mail address: 